Forum 2019 · 34:217

https://doi.org/10.1007/s12312-019-0586-5

Online publiziert: 21. Februar 2019

(c) Springer Medizin Verlag $\mathrm{GmbH}$, ein Teil von

Springer Nature 2019

NIEDERSÄCHSISCHE

$\because:$ KREBSGESELLSCHAFT E.V.

Niedersächsischen Krebsgesellschaft e. V.

Hannover, Deutschland

\title{
Benefizkonzert anlässlich des Weltkrebstags
}

Harfenistin Isabel Moreton sowie an den großartigen Stimmen des Bachchor und des Mädchenchor Hannover (• Abb. 1, 2 und 3 ).

In einer bewegenden Ansprache rief die Theologin Dr. Margot Käßmann dazu auf, über Krebserkrankungen und den Tod nicht zu schweigen und sprach in Anlehnung an Ps 90,12 „... auf das wir klug werden." über die Sinnfrage bei Krebserkrankungen.

Emotionaler Höhepunkt des Abends, welcher von dem NDR-Moderator ArneTorben Voigts moderiert wurde, war ein berührendes Kerzenritual zum Gedenken an vom Krebs betroffene und am Krebs verstorbene Menschen.

Der wunderschöne Abend des kostenfreien Benefizkonzerts wurde mit zahlreichen Spenden für die Arbeit der Niedersächsischen Krebsgesellschaft honoriert.

\section{Korrespondenzadresse}

\section{Jennifer Schiller}

Niedersächsische Krebsgesellschaft e.V. Königstr. 27, 30175, Hannover, Deutschland schiller@nds-krebsgesellschaft.de

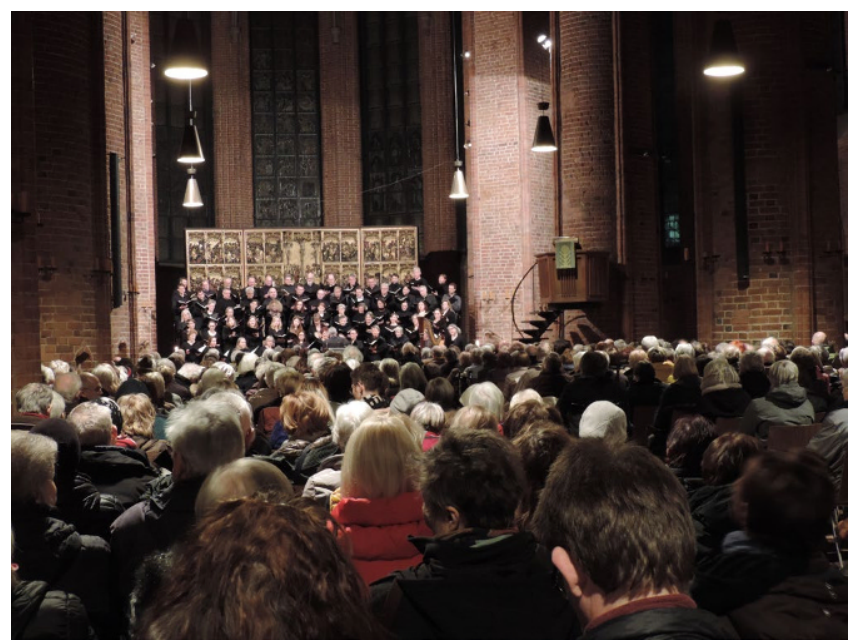

Abb. $1<$ Der Bachchor Hannover singt in der vollbesetzten Marktkirche in Hannover. (৫) Niedersächsische Krebsgesellschaft, mit freundlicher Genehmigung)

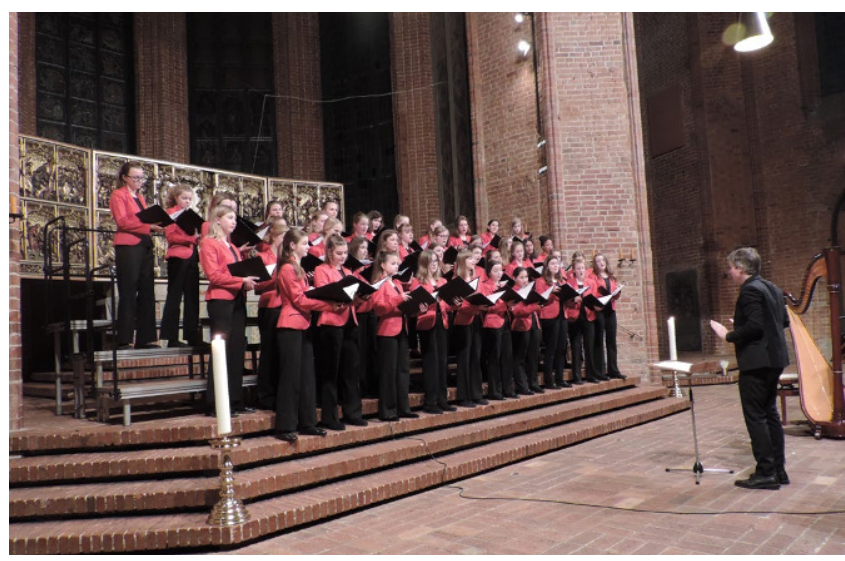

Abb. $2 \triangleleft$ Der Mädchenchor Hannover beim Benefizkonzert. (৫) Niedersächsische Krebsgesellschaft, mit freundlicher Genehmigung)

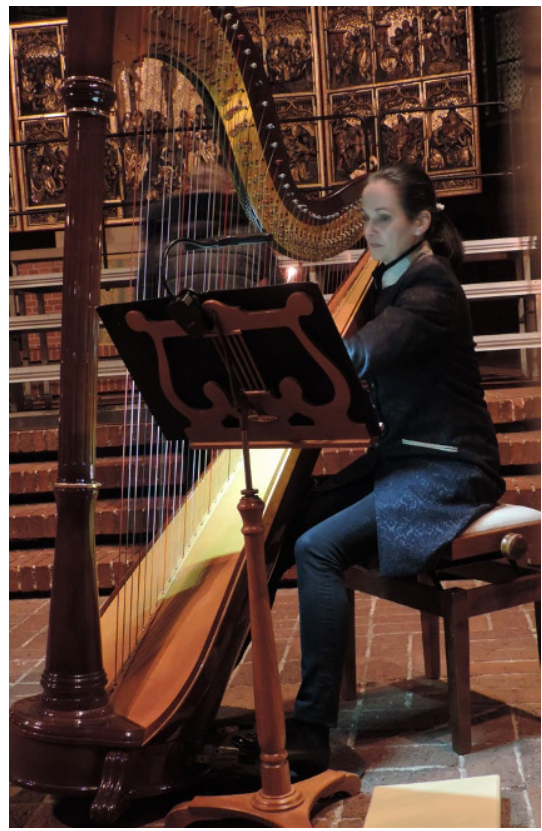

Abb. $3 \Delta$ Isabel Moreton verzaubert mit sanften Harfenklänge. (@ Niedersächsische Krebsgesellschaft, mit freundlicher Genehmigung) 